\title{
Nuit Debout: a nova barricada de Paris?
}

\section{Marcia Camargos}

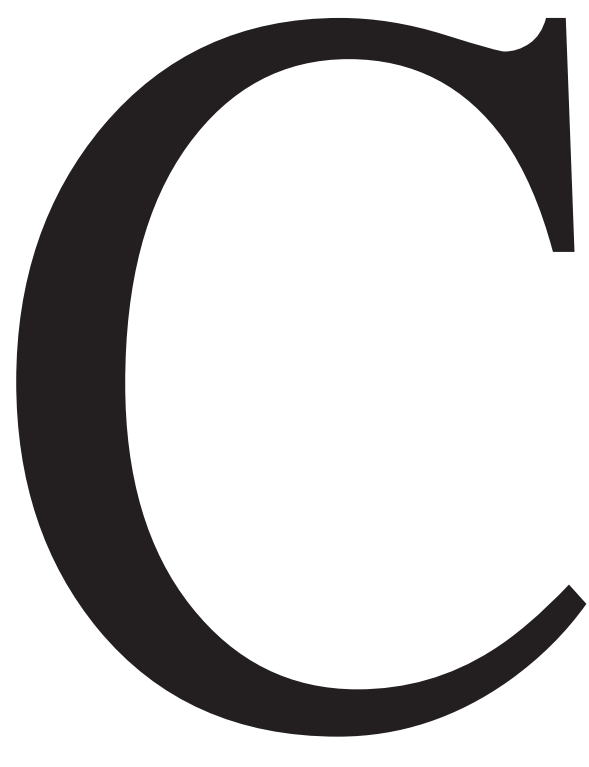

ontra as minas terrestres, a caça aos animais selvagens, o abate de bovinos, "que sofrem como nós", contra o apartheid palestino, a perseguição aos curdos, a insegurança no bairro chinês, a islamofobia, a violência de Estado, as guerras, a Lei do Trabalho ou o governo golpista de Michel Temer. Escolha a sua causa e levante a sua bandeira. Na Place de la République, na interseção entre três distritos, os arrondissements da capital francesa, cabem todos os protestos.

Local preferido dos insatisfeitos de plantão, ela tornou-se o ponto de partida ou chegada das manifestações cada vez mais frequentes na cidade. Isso, apesar do Estado de urgência em vigor, dando poderes extraordinários à polícia e proibindo as aglomerações. Resposta do governo François Hollande aos atentados terroristas que se abateram sobre a França, e medida preventiva contra futuros ataques, foi decretado na tarde de 14 de novembro de 2015 em todo o território nacional. Oficialmente ainda em vigor, acabou relaxado, pouco a pouco, diante da crescente pres- 
são da opinião pública, dos movimentos sociais e dos sindicatos, que contestam as interdições. Dia sim, dia não, eles fecham o trânsito com passeatas de todo tipo e tamanho que, não raro, terminam em confrontos com a polícia, além de detenções e feridos. E embora não se possa falar em reedição de maio de 68 , quando uma greve geral rapidamente superou barreiras de classe, idade e etnia, convertendo-se em insurreição popular, marcando a história do século XX, nota-se um nítido clima de descontentamento no ar.

A crise econômica, agravada pelo drama dos refugiados, que chegam em levas sucessivas, enchem as ruas de sem-teto. Nas periferias, vagam sem emprego jovens negros ou descendentes de árabes que, marginalizados e sem perspectivas, tornam-se presa fácil dos discursos religiosos extremistas. As próximas eleições presidenciais, que apontam o crescimento da direita, nas candidaturas de Marine de Le Pen, da Frente Nacional, e de Nicolas Sarkozy, galvanizam as atenções, desafiando as esquerdas. Nesse contexto, a Place de la République tornou-se um locus privilegiado de resistência, talvez nos moldes da Praça Tahrir, no Cairo, no processo da derrubada do ditador Hosni Mubarak.

Estendendo-se por 3,4 hectares, o equivalente a 34 mil metros quadrados, ou quatro campos de futebol, ela presta-se com louvor à função de acolher os que protestam. Quem não se lembra das imagens, veiculadas à exaustão mundo afora, da multidão que tomou cada centímetro das suas calçadas, logo após o assassinato da equipe de redação do jornal Charlie Hebdo? E das homenagens, em forma de buquês de flores, velas, cartazes, desenhos, faixas, flâmulas, brinquedos, bilhetes e grafites, que quase submergiam o monumento de 23 metros de altura, sobre o qual desponta uma figura feminina em bronze?

Recolhidos a partir do início de agosto de 2016, os objetos, agora armazenados em um arquivo da Prefeitura, abrem espaço para que melhor se admire a obra no topo do pedestal. De pé, vestida com uma simples toga, a estátua de Marianne personifica a República Francesa nos seus 9,4 metros de imponência e glória. Na cabeça traz uma coroa de louros e um barrete frígio, usado em 1793 pelos sans-culottes durante a Comuna de Paris. Na mão direita carrega um ramo de olivas, símbolo da paz e da prosperidade. Na esquerda repousa uma tábua com as inscrição "Droits de l'Homme".

Originalmente Place du Château d'Eau, nome derivado da enorme fonte de 1811, saída da prancheta de Pierre-Simon Girard para trazer água direto de La Villette, era toda decorada com leões, assim como a sua sucessora, de 1867 , segundo projeto de Gabriel Davioud. Mas foi por ocasião das drásticas remodelações urbanísticas do barão de Haussmann, responsável pelo embelezamento e higienização da capital, livrando-a das ruelas e becos propícios às barricadas, que a praça ganhou o formato atual. O monumento que viria a substituir a segunda fonte, criado pelos irmãos Léopold e Charles Morice, resultou de uma competição anunciada em 1879 pela Prefeitura de Paris, para comemorar o nonagésimo aniversário da Revolução Francesa.

Tanto a coluna, que sustenta Marianne, quanto as três esculturas em pedra para as quais serve também de encosto, assim como outros elementos decorativos, entre florões, placas e brasão de Paris, estavam cobertas de pichações. Devidamente recuperadas na recente limpeza, elas mostram, cada qual, uma alegoria de um termo da divisa do ideal republicano. São os célebres "igualdade, liberdade e fraternidade", valores iluministas presentes em boa parte dos edifícios públicos do país. Contudo, sua transformação em área 70\% pedestre ocorreu no mandato do prefeito Bertrand Delanoe, que, em 2008, fez da remodelação da République uma de suas principais promessas de campanha.

\section{OCUPAR E RESISTIR}

"Guerra aos tiranos, paz entre os povos." Com este mote, os integrantes da Nuit Debout convidam os revoltosos a convergirem rumo a um ponto comum, compartilhando o mesmo objetivo. Tarefa nada simples, em face do número de reivindicações presentes nessa que se tornou a Meca dos revolucionários, independente da origem, credo ou modus operandi. Para se ter uma ideia da multiplicidade de propostas encontradas nos limites da Place de la République, basta dizer que no domingo, 24 de setembro, ao menos dez diferentes causas eram defendidas com ardor por seus ferrenhos militantes. 
De um lado, moças e rapazes seminus, envoltos em plástico, para simular embalagens a vácuo, pregavam o fim da matança e do consumo da carne animal. Sob o sol forte do início de outono, expunham seus corpos tingidos de vermelho como se fossem mercadoria na prateleira refrigerada de um supermercado. Para reforçar a mensagem, logo em frente, um senhor vestido de açougueiro oferecia aos transeuntes partes humanas de mentirinha, desafiando-os a experimentar um tornozelo, coxa ou globos oculares ao vinagrete. Os veganos dividiam espaço com os que combatem a crueldade contra os animais selvagens, igualmente "perseguidos e necessitando nossa proteção", conforme apontou uma das ativistas.

No extremo oposto, em um lugar fechado, ao qual só se tinha acesso após uma revista de bolsas e sacolas, como tornou-se praxe para entrar até em lojas e cinemas, erguia-se uma pirâmide de calçados. Era o recado da ONG Handicap International que, desde 1995, vem lutando contra a proliferação das minas terrestres e uso de armas explosivas em zonas povoadas. Uma mostra ao ar livre trazia fotografias e relatos de vítimas e de profissionais engajados na remoção e destruição dos artefatos que, apenas em 2016, mutilaram 4 mil pessoas em 80 países. Ao final do percurso, os visitantes eram convidados a contribuir com um par de sapatos, tênis, bota ou sandália para a montanha simbólica, e a assinar uma petição.

Ao longo da praça, sob tendas, sentados em baquetas como numa roda de conversa, grupos distintos discutiam todo tipo de assunto, que iam da situação na Inglaterra pós-brexit, estratégias para enfrentar o Medef, o sindicato patronal, à situação explosiva da "Jungle" de Calais - como intitula-se o campo de refugiados daquela cidade portuária. Enquanto isso, nas laterais, uma passeata multiétnica reunia gregos e baianos. Nela viam-se manifestantes sob o arco-íris gay, outros pedindo o boicote aos produtos de Israel. Colombianos gritavam pela paz na sua terra devastada pelo narcotráfico e membros da comunidade curda reivindicavam a libertação de Abdullah Öcalan, cofundador do Partido dos Trabalhadores do Curdistão, (PKK), condenado à prisão perpétua na Turquia. Fechando a marcha, vinham os brasileiros com o panteão verde-amarelo e cartazes de "Casse toi Temer" e "Fora Temer".
Pairando sobre esse caldo político-cultural como um guarda-chuva protetor, encontra-se a organização autodenominada Nuit Debout. Traduzido para algo como "Noite em Vigília", procura aglutinar e apoiar os setores da sociedade civil que buscam a praça para ecoar seu desagrado. Surgido em 31 de março de 2016, no rastro de uma grande manifestação com cerca de 150 mil pessoas contra a Lei do Trabalho, realizada duas semanas antes, o movimento, que se diz plural e apartidário, busca a convergência das lutas. Seu alvo? A contestação global das instituições políticas e do sistema econômico. Sem porta-vozes, líderes ou hierarquia, organiza-se em comissões de coordenação, logística, atendimento e comunicação, ao passo que a tomada de decisões se faz por meio de assembleias gerais, democráticas e participativas.

Servindo de exemplo para outras cidades francesas, o coletivo de vigília progressivamente montou uma infraestrutura básica para permanecer no local o máximo de tempo possível. Instalam-se enfermaria, cantina, turnos de limpeza, de informações e de acampamento. Formaram-se equipes que incluem estudantes, operários, precarizados, imigrantes, universitários e desempregados de diferentes matizes políticas. Como uma ágora grega contemporânea, a praça evoca as ocupações da Porta do Sol em Madri, pelos Indignados, em 2011, e a Syntagma em Atenas, tomada pela "Geração dos 700 Euros". Inspira-se ainda, dizem, nas ações do Occupy Wall Street, movimento que, a partir de 17 de setembro de 2011, instalou-se no Zuccotti Park, no distrito financeiro de Nova York. Horizontal e espontâneo vinha denunciar a desigualdade, a corrupção e a ingerência das grandes corporações nos negócios do Estado, para seu próprio benefício, em detrimento dos outros $99 \%$ da população norte-americana.

\section{"NÓS SOMOS MILHÕES"}

Para embalar as centenas de insatisfeitos que fazem da République uma extensão das suas casas, a Orquestra Debout promove sessões quase diárias. Sem um corpo artístico fixo nem uma seleção de músicas predeterminada, escolhe o repertório ao sabor do momento. Em uma das demonstrações de brasileiros contra o impeachment, pouco antes 
da destituição da presidente Dilma Rousseff, por exemplo, podia-se escutar os acordes de "Apesar de Você", de Chico Buarque de Holanda. Era a praça honrando seu viés internacionalista, uma das prioridades da ocupação.

Mas nem tudo é paz e amor nesta ilha da Utopia. Nas noites de 14 e 15 abril, o chefe de polícia, lamentando a presença de pequenos grupos violentos, mandou a CRS, sigla da Companhia Republicana de Segurança, criada em 1944 por decreto do general Charles de Gaulle, dispersar os ocupantes. Estes, por sua vez, acusaram a forças da ordem de infiltrarem agentes provocadores para desmoralizar a Nuit Debout. Dali a uma semana, novos enfrentamentos, com o saldo de um automóvel em chamas e a convocação para uma "jornada temática" sobre o tópico da violência. No fim do mês, os ocupantes foram evacuados com uso de bombas de efeito moral e balas de borracha. Mesmo sem opor resistência, e já algemados, alguns acabaram agredidos. Os confrontos prosseguiram no $1^{\circ}$ de Maio. Após incidentes registrados no desfile comemorativo da data, a polícia ordenou a dispersão da Nuit Debout, retirando 600 militantes à força. Em seguida, em comunicado oficial, o governo endureceu o discurso, tornando ainda mais difíceis as condições de reunião. Nenhuma das medidas, porém, conseguiu arrefecer os ânimos daqueles que, nas palavras de Alan, um dos seus ativos participantes, não têm nada a perder. Principalmente, diz ele, nesta Quinta República que degrada o meio-ambiente, exerce a dominação, reprime e descrimina, além de sustentar a ditadura do mercado financeiro, empoderando as multinacionais, responsáveis pela corrupção das instituições.

"Nós denunciamos as grandes potências que favorecem os tráficos, o deslocamento de populações e o comércio de armas", ressalta, em meio ao barulho da praça efervescente, para acrescentar que este é um movimento informal e espontâneo, cuja autoestruturação evolui de acordo com as necessidades. "Estamos abertos a todos, dentro do respeito ao trabalho coletivo. Atuamos de forma independente e comum, na busca de alternativas concretas para a elaboração de soluções globais", continua. Nesta direção, explica, "segue a proposta de transformar os espaços públicos em locais de expressão criativa, de práticas solidárias, de troca e difusão de saberes, elevando o nível das consciências e das motivações, num clima de igualdade e fraternidade, livre de preconceitos".

Indagado qual seria o valor mais importante a unir essa verdadeira fauna revolucionária, o rapaz magro, de cabelos loiros encaracolados batendo quase na cintura, não hesita: "O anticapitalismo e a oposição incansável ao sistema, com todas as suas injustiças". Com um distinto sorriso, enumera o extenso cardápio de atividades programadas para os meses vindouros. Contemplam, entre a série de eventos, uma jornada pela melhoria das condições gerais de trabalho, marcha pelos refugiados e debate sobre a educação popular. Do alto dos seus 34 anos, confidencia que cogitam, no curto prazo, impedir as eleições presidenciais. Como levarão a cabo tão ousado desafio?

"Vamos tomar os locais de votação. Ninguém entra para depositar sua escolha nas urnas.” E, com uma determinação quixotesca, refletida nos olhos azulados, conclui: "Eles precisam ouvir a nossa voz. Afinal de contas, somos milhões".

Portanto, para quem vier a Paris, seja a trabalho ou a lazer, recomendo fortemente um passeio pela praça. Inclusive aos céticos e pessimistas - ou sobretudo a eles. Para além da sua relevância como patrimônio histórico e cultural, a Place de la République vale por esse aspecto humano que revigora os ânimos, alimentando nosso mirrado arsenal de esperança. Mesmo que por poucas e fugazes horas, na Nuit Debout aprendemos que sonhar é possível. Resistir, também. 